The Spectrum of

Clean Energy Innovation

\title{
NREL Produces Highly Efficient, Wide-Bandgap, Thin-Film Solar Cells
}

Researchers at the National Renewable Energy Laboratory (NREL) are finding new ways to manufacture thin-film solar cells made from copper, indium, gallium, and selenium-called CIGS cellsthat are different than conventional CIGS solar cells. Their use of the high-temperature glass, designed by SCHOTT AG, allows higher fabrication temperatures, opening the door to new CIGS solar cells employing light-absorbing materials with wide "bandgaps." A bandgap is the minimum energy required for a photon (a particle of light) to free an electron from the material and create an electrical current.

Wide-bandgap cells can perform at higher operating temperatures and produce higher output voltages, which provide advantages in certain conditions. Low-bandgap cells can lose $25 \%$ of their power output and efficiency ratings as solar cell operating temperatures climb to $75^{\circ} \mathrm{C}$ or more, a common occurrence in hot and arid lands where solar resources are plentiful.

In contrast, CIGS solar cells with wide bandgaps can function at higher efficiencies regardless of temperature. NREL researchers have been able to make CIGS solar cells with bandgaps greater than 1.2 electron volts (eV) that will lose only about $10 \%$ of their output at $75^{\circ} \mathrm{C}$. Currently, commercial CIGS cells have a $1.1 \mathrm{eV}$ bandgap. The higher voltage of the wide-gap cells results in reduced recombination, meaning electrons are not lost in the CIGS absorber layer but continue as "free" electrons, contributing to the cell's electrical current and voltage. Therefore, at high temperatures, a wide-bandgap cell is capable of more energy output than a low-bandgap cell with the same wattage or power rating.

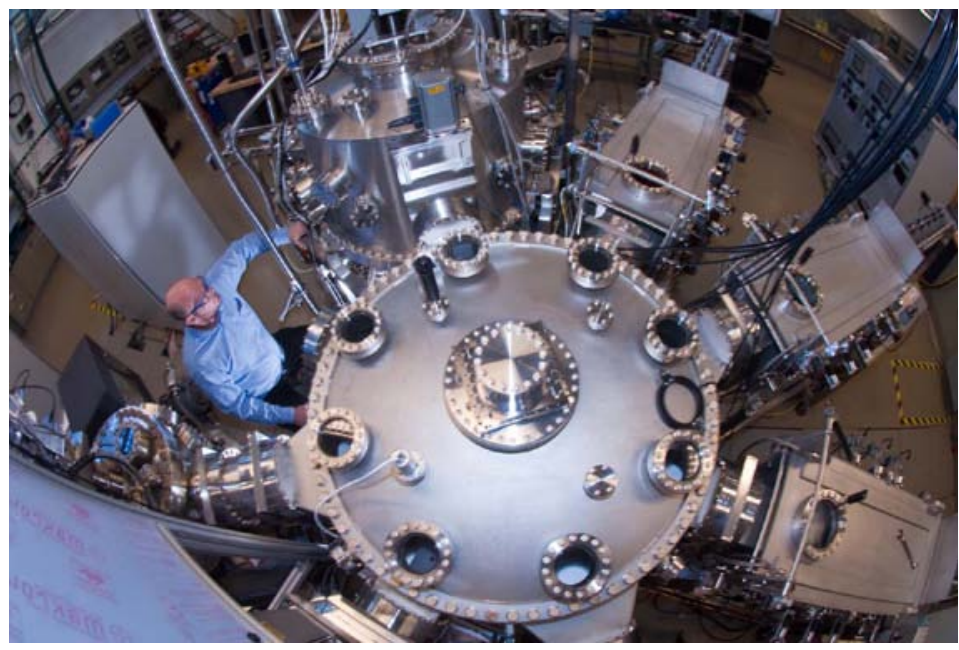

NREL's CIGS tool, shown here, has helped drive the research into highly efficient, wide-bandgap CIGS solar cells. Photo by Patrick Corkery, NREL/PIX 17161

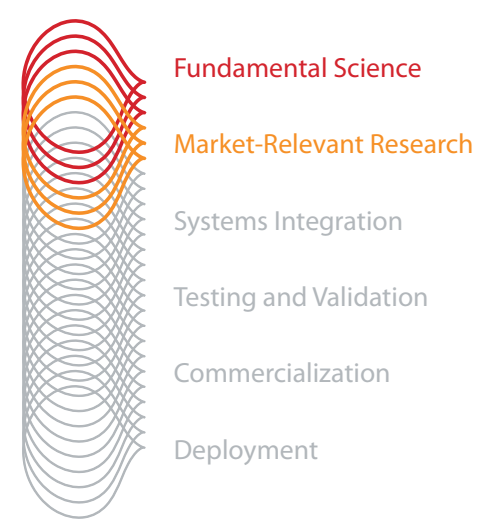

Through deep technical expertise and an unmatched breadth of capabilities, NREL leads an integrated approach across the spectrum of renewable energy innovation. From scientific discovery to accelerating market deployment, NREL works in partnership with private industry to drive the transformation of our nation's energy systems.

This case study illustrates NREL's innovations in Fundamental Science through Market-Relevant Research

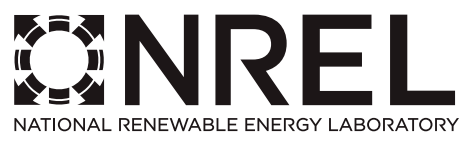

NREL is a national laboratory of the U.S. Department of Energy, Office of Energy Efficiency and Renewable Energy, operated by the Alliance for Sustainable Energy, LLC. 
The path to this innovation began in 2009, when NREL researchers decided to revisit some experimental work done in the mid-1990's using higher amounts of gallium in CIGS. Back then, an NREL team looking for efficiency improvements fell short of attaining high-efficiency cells. Still, researchers learned valuable lessons about the process of cell fabrication, as well as the substrate limitations. They determined that their main barrier to overcome was the availability of a glass substrate material that could withstand fabrication temperatures $>600^{\circ} \mathrm{C}$ without deformation. A CIGS absorber is typically fabricated at temperatures of $500-600^{\circ} \mathrm{C}$, and using that, commercially manufactured modules have obtained efficiencies approaching 16\%. But researchers recognized that there was a greater potential efficiency.

In 2009, NREL researchers and scientists from glass manufacturer SCHOTT AG began discussing the use of the company's specialty high-temperature photovoltaic (PV) glass in cell fabrication. The new PV glass allowed fabrication at temperatures around $630^{\circ}-650^{\circ} \mathrm{C}$, overcoming the former barrier to higher-efficiency cells. In addition, the SCHOTT glass has a coefficient of thermal expansion matched to the CIGS process, so both the glass and the film will expand and contract at the same rate.

NREL scientists already knew that the higher temperatures would help improve efficiencies in high-gallium CIGS solar cells. To test the new glass and CIGS solar cells made on it, the team used substrate temperatures of up to $650^{\circ} \mathrm{C}$ to deposit semiconductor materials as part of the process that leads to high-efficiency CIGS solar cells. The first high-gallium CIGS cells that the NREL researchers manufactured were small-area devices, with a cell area less than 1 square centimeter. The lessons learned are now being applied to mini-modules ( 200-square-centimeter devices) that are being fabricated in NREL's Process Development and Integration Laboratory (see sidebar). The cells register a conversion efficiency greater than 19\%. So far, only the SCHOTT PV glass allows these higher efficiencies in wide-bandgap CIGS solar cells.

Additional work is needed in two fronts: further improvements to the CIGS absorber and new and alternative CIGS solar cell structures to replace some of the materials in the conventional cell structure that limit current generation. These include the transparent conductive oxides (TCOs) that form the top layer and one electrical contact for the cell, as well as the buffer layers between the active layers of the cell.

For instance, cadmium sulfide forms the buffer layer between the CIGS absorber and the zinc oxide TCO, and it significantly limits the current output from the cell. NREL researchers think that if they could replace the cadmium sulfide with another widergap buffer, additional current gains could lead to even higher efficiencies.

There are several key implications to NREL's work. First, this can be considered a breakthrough in energy conversion efficiency for the wide-bandgap, high-gallium CIGS solar cells enabled by SCHOTT glass_-something that researchers around the world have been pursuing for decades, but no one had successfully accomplished. Second, the findings point to more efficient and reliable CIGS products. Taken together, these innovations could herald very significant impacts to the thin-film solar cell industry.

\section{CIGS Cluster Tool Capabilities Drive Innovation}

The CIGS cluster tool in NREL's Process Development and Integration Laboratory (PDIL) has driven innovation and industry collaborations. The tool consists of integrated, interconnected vacuum chambers for depositing, processing, measuring, and characterizing CIGS materials and devices.

The CIGS thin-film solar cell industry has a variety of processes for deposition of the layers the device comprises, especially the CIGS absorber layer. While processes using vacuum evaporation have demonstrated high performance efficiency (11\%-13\%) in commercial modules and greater than $20 \%$ efficiency in small-area, laboratory-scale solar cells, they have a relatively low throughput and low material utilization-meaning that many of the elements composing the CIGS material are lost in the process.

The PDIL CIGS tool incorporates alternate fabrication methods such as sputtering - a vapor method that deposits thin films from a "target" after the target is bombarded with ionized argon gas. In addition to the CIGS tool, PDIL capabilities include chemical vapor deposition, in which the substrate is exposed to volatile precursor gases that react on the substrate surface to produce the desired film.

Other non-vacuum techniques available in the PDIL include: electro-deposition, in which particles suspended in a liquid medium migrate towards the substrate under the influence of an electric field, and the atmospheric processing of CIGS using precursor inks containing copper, indium, gallium, and selenium that can be sprayed or printed onto a substrate. Sputtering, electrodeposition, and other non-vacuum processes for CIGS fabrication lag behind in performance compared to evaporation, but they have other demonstrated manufacturing advantages, such as better material utilization, lower intrinsic costs, and easier scale-up.

\section{National Renewable Energy Laboratory}

15013 Denver West Parkway

Golden, CO 80401

303-275-3000 • www.nrel.gov

NREL is a national laboratory of the U.S. Department of Energy, Office of Energy Efficiency and Renewable Energy, operated by the Alliance for Sustainable Energy, LLC.

NREL/FS-6A42-51559 • September 2012

Printed with a renewable-source ink on paper containing at least $50 \%$ wastepaper, including $10 \%$ post consumer waste. 